\title{
PERCURSOS HISTÓRICOS DE ENSINAR CIÊNCIAS ATRAVÉS DE ATIVIDADES INVESTIGATIVAS'
}

\author{
Guilherme Trópia Barreto de Andrade**
}

RESUMO: Este trabalho discute momentos históricos em que a perspectiva do ensino por atividades investigativas foi debatida por estudiosos da Educação e da Educação em Ciências. Recorro aos trabalhos de John Dewey no início do século XX que propõem a investigação na escola a partir do método científico. Apresento as reformas curriculares em 19501960 no ensino de Ciências no Brasil em que materiais didáticos propunham a realização de investigações científicas. E por fim, discorro sobre a retomada da perspectiva investigativa no final do século XX com discussões sobre a natureza da Ciência e relações entre a Ciência e a sociedade no ensino de Ciências. Aponto que os fundamentos da perspectiva investigativa no ensino de Ciências estão intimamente relacionados às concepções de Ciência em discussão em cada momento histórico.

Palavras-chave: Ensino de Ciências; Atividades Investigativas, História do Ensino de Ciências.

\section{HISTORICAL TRAJECTORIES OF INOUIRY IN SCIENCE EDUCATION}

ABSTRACT: In this paper, I discuss historical moments in which the perspective of inquiry Education was debated by Science Education and Education researchers. I have investigated John Dewey's papers in the beginning of the 20th century that proposes the inquiry perspective at school, using the scientific method. I have investigated the curriculum reforms on the Science Education in Brazil during the decades of 19501960 in which the didactic material recommended the scientific inquiry. And at last, I investigated a recovering of the inquiry perspective in the end of the 20th century, influenced by discussions about the nature of Science and the relations between Science and Society in Science Education. I point out that the bases of the inquiry perspectives in Science Education are intimately connected to the conceptions of Science in discussion at each historical moment.

Keywords: Science Education; Inquiry Activities; History of Science Education.

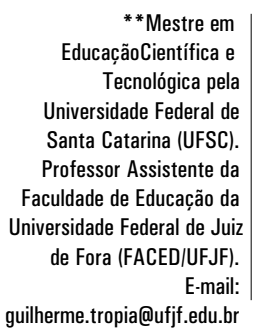

guilherme.tropia@ufjf.edu.br 


\section{INTRODUĈ̣̃O}

A prática de ensinar Ciências por atividades investigativas vem assumindo historicamente a perspectiva de trazer a atividade científica dos cientistas para o ensino de Ciências, em um movimento de aproximar os conhecimentos científicos dos conhecimentos escolares. Neste trabalho de cunho teórico, apresento os fundamentos dessa prática de ensino em momentos históricos diferentes na qual essa perspectiva foi discutida por estudiosos da Educação e do ensino de Ciências. Os fundamentos da perspectiva investigativa como prática de ensino de Ciências na escola modificaram ao longo do século XX. Esses fundamentos estão intimamente relacionados às concepções de investigação científica e, consequentemente, de Ciência em discussão em cada momento histórico.

Barrow (2006) apresenta uma breve história sobre ensino de Ciências por investigação, enfocando o contexto educacional norteamericano. Este trabalho, entretanto, focaliza o ensino de Ciências por atividades investigativas no contexto educacional brasileiro, discutindo algumas influências que esse recebeu de propostas educacionais estrangeiras.

Inicialmente, recorro aos trabalhos de John Dewey no início do século XX que propõem a perspectiva investigativa na escola, a partir do método científico. Em seguida, apresento as reformas curriculares no ensino de Ciências nos EUA e no Brasil nas décadas de 1950 e 60 em que os materiais didáticos tinham como fundamento levar a prática científica para o ensino de Ciências. A investigação científica presente nesses materiais tinha uma concepção de Ciência neutra, afastada da sociedade. Em seguida, discorro sobre uma retomada do ensino de Ciências por atividades investigativas no final do século XX e que vem se difundindo no Brasil. Essa retomada difere das perspectivas anteriores por influência das discussões sobre a natureza da Ciência e da apropriação de relações entre a Ciência e a sociedade no ensino de Ciências.

\section{O ENSINO POR ATIVIDADES INVESTIGATIVAS EM JOHN DEWEY}

O termo "investigação" como estratégia para o ensino de Ciências utilizado no Brasil vem da tradução do termo inquiry ou enquiry de países de língua inglesa. De acordo com Barrow (2006), a inclusão da perspectiva investigativa na Educação Científica, nível K-12 $2^{2}$ nos EUA, foi proposta por John Dewey no início do século passado?.

Dewey é reconhecido como um pensador de vanguarda no pragmatismo e na Educação progressista nos EUA, sendo o educador estadunidense mais considerado do século XX. Teitelbaum \& Apple (2001) afirmam que as idéias de Dewey são tanto respeitadas pelo seu compromisso com a Educação progressista e políticas democráticas quanto criticadas pelo seu provável papel na fragilização da escolarização norteamericana. 
As idéias de Dewey surgiram em um contexto onde o desenvolvimento econômico, baseado em interesses capitalistas nos EUA, no início do século $\mathrm{XX}$, silenciava as desigualdades e os conflitos sociais. As empresas, ao concentrar os negócios, geravam grandes monopólios visando o aumento da produtividade e eram indiferentes ao bem-estar social de seus trabalhadores.

De acordo com Pessoa-Pinto (2004), Dewey se preocupava com a crise de valores em que a sociedade se encontrava em decorrência das rápidas mudanças ocorridas nos meios de produção. Suas inquietações focavam tanto o estabelecimento das novas relações de trabalho quanto a estagnação de instituições sociais que não acompanhavam essas mudanças, discutindo os conflitos éticossociais que emergiam naquele contexto. Umas dessas instituições era a escola.

Um marco importante desse momento histórico foi a queda da bolsa de Nova Iorque em 1929 e o subsequente conjunto de medidas governamentais para conter o desemprego da classe trabalhadora e a falência das empresas decorrente da crise econômica. Essas medidas ficaram conhecidas como New Dealt e desencadearam um forte movimento das organizações sindicais que se aliaram às ideias do movimento progressista norteamericano. Segundo Cunha (2001), esses movimentos buscavam regulamentar o trabalho nas fábricas, como o trabalho de mulheres, combate ao trabalho infantil, indenizações por acidentes durante o serviço, melhoria nas condições de vida dos trabalhadores. Foi nesse quadro que as ideias de Dewey surgiram, discutindo a Educação escolar como possibilidade de construir uma sociedade mais humanizada a fim de contribuir para a instituição de um projeto democrático ${ }^{5}$.

Diante desse quadro, Dewey reconstrói a concepção de conhecimento vigente de forma a integrar os objetos da Ciência ao domínio das atividades humanas, o que ele chamou de "experiência". "Deste modo, as coisas que são de importância suprema para a vida humana não seriam mais depreciadas, nem pareceria mais absurdo que a Ciência viesse a se ocupar também com questões desse âmbito" (PESSOA-PINTO, 2004, p. 2).

Segundo Pessoa-Pinto (2004), as Ciências Naturais exerceram forte atração sobre Dewey, o que é constatado em suas referências ao poder de controle e de transformação dessa Ciência sobre o meio ambiente, que permitiu a produção cada vez mais segura de bens que elevaram o grau de conforto e de bem-estar do homem. Para o pensador, a Ciência se constitui como um método de observação, reflexão e verificação, onde se revê convicções vigentes a fim de excluir delas o que é errôneo, aumentando sua exatidão. Os conhecimentos científicos, e especificamente da Ciência experimental, são fatores por meio dos quais "as experiências passadas são purificadas e convertidas em instrumentos para as descobertas e para o progresso" (DEWEY, 1959, p. 248). Dewey se apropria da concepção de método científico como um conjunto de etapas que caracterizam a investigação científica. Assim, o conhecimento para Dewey busca, a partir da utilização do método científico, refletir a possibilidade de atuação em questões sociais e morais. 
Com a integração das duas esferas, seria possível, então, utilizar o Método Científico, de eficácia já comprovada no âmbito da natureza física, à resolução da crise de valores que a própria ciência gerou, de forma a restituir o bem-estar ao ser humano. (PESSOA-PINTO, 2004, p. 2)

Para Dewey (1971), o método científico seria um modelo eficaz para utilizar as experiências dos estudantes “(...) para delas extrairmos luzes e conhecimentos que nos guiem para frente e para fora em nosso mundo em expansão" (DEWEY, 1971, p. 93). Tal método consistia em: definição do problema, sugestão de uma solução, desenvolvimento e aplicação do teste experimental e formulação da conclusão. Apesar do caráter instrumentalista, o método científico proposto por Dewey (1959) visava “(...) nutrir uma compreensão e uma plena convicção da possibilidade de direção das coisas humanas (...)” (DEWEY, 1959, p. 247), no intuito de desenvolver uma sociedade mais democrática.

Segundo Teitelbaum \& Apple (2001), as ideias de Dewey não foram instituídas formalmente no sistema educacional americano provavelmente pelo fato de suas destas serem resistentes ao modelo político econômico da época. Assim, a perspectiva investigativa na prática escolar proposta por Dewey não foi implementada institucionalmente nas escolas norteamericanas. No entanto, a idéia de trazer a investigação científica para a sala de aula, e especificamente para o ensino de Ciências, é retomada em meados do século XX tanto nos EUA quanto em outros países, sendo influenciada pelas reflexões de John Dewey.

\section{O ENSINO DE CIÊNCIAS POR ATIVIDADES INVESTIGATIVAS NAS REFORMAS CURRICULARES NAS DÉCADAS DE 1950 E 1960}

As reformas curriculares no ensino de Ciências no Brasil nas décadas de 1950 e 60 se situam em um momento histórico que "a sociedade brasileira se ressentia da falta de matéria-prima e produtos industrializados durante a $2^{\mathrm{a}}$ Guerra Mundial e no período pós-guerra, pois buscava superar a dependência e se tornar autossuficiente" (KRASILCHIK, 2000, p. 86). Segundo Krasilchik, o processo de industrialização do Brasil dependia do progresso da Ciência e da Tecnologia e, assim, as mudanças curriculares no ensino de Ciências preparariam os jovens para suprir a demanda de pesquisadores que impulsionariam o desenvolvimento científico e o consequente progresso do país. O cerne dessas reformas curriculares era trazer a investigação científica para o ensino de Ciências, o que foi desenvolvido a partir de projetos do IBECC - Instituto Brasileiro de Educação, Ciência e Cultura -, criado em 1946 e com a tradução de materiais didáticos produzidos nos EUA e Inglaterra na década de 60.

De acordo com Barra \& Lorenz (1986), o IBECC tinha papel de promover melhorias na formação científica dos alunos que ingressariam nas instituições de ensino superior. Para tal função, o IBECC formulou projetos para 
melhorar o ensino de Ciências nas escolas de nível básico. Os projetos visavam o desenvolvimento de investigações científicas pelos alunos através da introdução do método experimental em sala de aula. Assim, os primeiros materiais produzidos pelo IBECC foram os kits de Química que consistiam em realização de experimentos. Esses kits foram comprados pelo Ministério da Educação e distribuídos nas escolas, além de serem disponibilizados para venda ao público. A partir dessa experiência foi instituído no IBECC um projeto chamado "Iniciação Científica" que produziu kits com manuais de instruções e leituras complementares que contemplavam conceitos de Química, Biologia e Física. O apoio financeiro para o desenvolvimento dos materiais procedia de capital estrangeiro ${ }^{6}$ e também do Ministério da Educação.

Esse primeiro movimento no Brasil com o IBECC buscava o desenvolvimento do ensino de Ciências e vinha de encontro com a crescente valorização da Ciência e da Tecnologia no cenário internacional. Um dos eventos importantes dessa época foi o sucesso técnico-científico do lançamento do Sputinik I russo em 1957, o que colocou a Rússia em evidência quanto ao desenvolvimento científico e tecnológico. Esse fato gerou uma reação nos países ocidentais, principalmente naqueles considerados desenvolvidos, como EUA e Inglaterra, que mobilizaram grande aporte de recursos humanos e financeiros para o desenvolvimento da Ciência e da Tecnologia. Parte desses recursos foi destinada ao desenvolvimento da Educação Científica e Tecnológica, incluindo a Educação Básica para incentivar jovens talentos a seguir carreiras científicas. Conforme aponta Krasilchik,

\footnotetext{
Na medida em que a Ciência e a Tecnologia foram reconhecidas como essenciais no desenvolvimento econômico, cultural e social, o ensino das Ciências em todos os níveis foi também crescendo de importância, sendo objeto de inúmeros movimentos de transformação do ensino, podendo servir de ilustração para tentativas e efeitos das reformas educacionais. (KRASILCHIK, 2000, p. 85)
}

Segundo Barrow (2006), os investimentos na Educação Básica em Ciências nos EUA se concentraram em duas questões: a qualidade dos professores de Ciências - Biologia, Química e Física - e o currículo de Ciências utilizado nas escolas. Assim, órgãos governamentais ligados à Educação Científica nos EUA produziram no final da década de 1950 e ao longo da década de 1960 materiais didáticos para as disciplinas escolares baseados em um projeto curricular inovador. A inovação consistia em promover o ensino de Ciências a partir do processo de investigação. Essa prática de ensino levava o aluno a participar de atividades que lhe possibilitavam "fazer" atividades científicas através do método experimental. Para a disciplina Biologia foi produzido um material denominado Biology Science Curriculum Study (BSCS) com três versões: azul, verde e amarelo. Para a Física foi produzido Physics Science Study Committe (PSSC) e para a Química Chemical Education Materials Syudy (Chem Study), dentre outros mate- 
riais produzidos ${ }^{7}$. Barrow (2006) aponta que a ênfase nesses materiais era levar o aluno a "pensar como cientista", levando-o a realizar processos de produção da Ciência a partir de etapas, como: observação, classificação, inferência, coleta de dados, controle de variáveis, interpretação dos dados e conclusão.

Dentro desse contexto, instituições que promoviam o desenvolvimento do ensino de Ciências nos EUA e Inglaterra começaram a alocar recursos para o mesmo fim em países da América Latina. Barra \& Lorenz (1986) situam a Fundação Ford (EUA) como subsidiária de investimentos financeiros para o IBECC a fim de produzir materiais didáticos de Ciências no início da década de 1960 no Brasil. Esse financiamento contemplava tradução e distribuição de materiais didáticos produzidos nos EUA, dentre eles o BSCS ${ }^{8}$, e cursos de formação de professores de Ciências'. Todos os materiais elaborados pelo IBECC para o ensino de Ciências eram baseados “(...) no conceito de Ciências como um processo de investigação e não só como um corpo de conhecimentos devidamente organizados" (BARRA \& LORENZ, 1986, p. 1973). Os materiais desenvolvidos com ênfase na investigação científica tinham uma perspectiva metodológica que visava planejar e executar experimentos com materiais acessíveis a fim de possibilitar a vivência dos alunos com o método científico.

\footnotetext{
No período das décadas de 1950-70, prevaleceu a idéia da existência de uma sequência fixa e básica de comportamentos, que caracterizaria o Método Científico na identificação de problemas, elaboração de hipóteses e verificação experimental dessas hipóteses, o que permitiria chegar a uma conclusão e levantar novas questões. (KRASILCHIK, 2000, p. 88)
}

Ferreira \& Selles (2005) analisaram dois volumes da versão azul traduzida para o português do BSCS. As pesquisadoras pontuam que o próprio texto do material supõe que o mais importante no ensino de Biologia é o aluno participar da investigação científica, desenvolvendo habilidades como observação e utilizar medidas e escalas. O processo de ensino por atividades investigativas, que é o caráter principal do BSCS, atribui a concepção da investigação científica como investigação experimental das Ciências Biológicas. Segundo Ferreira \& Selles (2005), a versão analisada do BSCS apresenta as características da atividade científica como estudos empíricos experimentais com explicações baseadas em modelos matemáticos, privilegiando uma concepção de Ciência empírica, objetiva e exata.

Krasilchik (2000) aponta que nos projetos curriculares das décadas de 1950 a 1970 a Ciência era considerada uma atividade neutra. O julgamento de valores dos cientistas e as condições de produção em que os cientistas estavam inseridos (contexto político, econômico, social) eram colocados à parte da atividade científica e de suas implicações na sociedade. Assim, os alunos, ao executarem as etapas do método científico no Ensino de Ciências de acordo com os manuais do BSCS e de outros materiais, vivenciavam o que hoje é considerado uma visão neutra e distorcida sobre a investigação científica. 


\section{NOVAS PERSPECTIVAS DO ENSINO DE CIÊNCIAS POR ATIVIDADES INVESTIGATIVAS}

A concepção de Ciência neutra que era contemplada no ensino Ciências por atividades investigativas nas reformas curriculares das décadas de 1950 a 1960 no Brasil, como apresentado no tópico anterior, se expressa em um movimento histórico de continuidade nas práticas de ensino de Ciências ao longo da segunda metade do século $\mathrm{XX}^{10}$. Moreira \& Ostermann (1993) apresentam cinco aspectos do método científico que consideram como concepções errôneas da atividade científica e que eram abordados nos livros didáticos e aulas de Ciências na escola durante a década de 1990. O primeiro aspecto refere-se ao início do método científico a partir da observação. Os autores discutem que a observação é uma atividade influenciada por conhecimentos prévios que o cientista já possui; ela está impregnada de teoria ${ }^{11}$. O segundo aspecto discute que a investigação científica não é um manual de algoritmos e etapas rígidas lineares a serem cumpridas. O terceiro se refere à perspectiva indutivista da Ciência dentro do método científico que atribui à construção de teorias científicas através da indução de leis a partir de fatos observados e analisados. O quarto aspecto discute a idéia de que o processo de produção da Ciência é cumulativo ou linear. Os autores apontam que o problema dessa perspectiva está no desenvolvimento da Ciência como acumulação de idéias, já que a construção da Ciência se dá por rupturas e reformulações do conhecimento prévio. E o último aspecto levantado é a questão que o conhecimento científico não é definitivo e que seria um erro apropriar-se do método científico no ensino de Ciências a fim de conceber os conhecimentos científicos como verdadeiros ou definitivos.

Entretanto, a partir da década de 1980, houve uma associação entre as práticas de ensinar Ciências através de atividades investigativas com perspectivas teóricas decorrentes das pesquisas em Educação em Ciências, como as concepções alternativas e a mudança conceitual (POSNER et al, 1982), alfabetização científica, enfoque CTS. No final da década de 1980 e início da década de 1990 há uma retomada da investigação como prática de ensino de Ciências que se instituiu em um segundo movimento de reformas curriculares nos EUA e na Inglaterra (DUSCHL, 2008). Nos EUA, o enfoque era levar "Ciência para todos" (Science for All), e na Inglaterra, o "Entendimento público da Ciência" (Public Understanding of Science), ambos com intuito de alfabetizar a população cientificamente a fim de que compreendessem um mundo no qual a Ciência e a Tecnologia cada vez mais influenciam aspectos políticos, econômicos e sociais.

Duschl (2008) aponta que para além de interesses sociais e econômicos, essas reformas curriculares enfocavam os imperativos culturais que apontam a apropriação de dimensões sociais e epistêmicas da Ciência necessárias ao desenvolvimento, avaliação e comunicação do conhecimento científico.

Assim, nessas reformas curriculares, a noção de investigação como prática de ensino de Ciências assume novas perspectivas. A investigação científi- 
ca desenvolvida pelos alunos e professores no contexto educativo contemplava importantes aspectos: (a) discussões sobre a natureza da Ciência nas investigações realizadas em sala de aula. A natureza da Ciência é incorporada ao ensino por investigação em um momento histórico em que discutir essa perspectiva com os alunos possibilitaria entender melhor o que é a atividade científica (SANDOVAL, 2005); (b) relações das atividades do ensino de Ciências por investigação com aspectos sociais. Essas relações entre Ciência e Sociedade no ensino de Ciências têm suas raízes em um movimento iniciado nas décadas de 1960 e 1970 denominado Ciência, Tecnologia e Sociedade (CTS) que buscava questionar a cultura tecnológica imposta pelas novas descobertas científicas durante a Segunda Guerra Mundial. Outro aspecto levantado pelo movimento CTS foi a discussão e indagação dos efeitos nocivos da produção científica decorrentes dessa época. Esse movimento buscou compreender não somente o produto das interações entre o social, a Ciência e a Tecnologia, mas visou contemplar o porquê e como surgiu. Nessa perspectiva, a Ciência passou a ser vista como algo cultural, dinâmico, submetida a diversas esferas, sejam elas políticas, religiosas, éticas, sociais, econômicas, contrapondo a concepção que a Ciência e a Tecnologia estejam separadas da sociedade.

A partir da retomada nas práticas de ensino de Ciências por investigação nos EUA e Inglaterra, outros países começaram a se apropriar dessas idéias. Abd-el-khalick et al (2004) apresentam experiências relatadas em um Simpósio Internacional que reuniu pesquisadores de seis países ${ }^{12}$ com realidades educacionais diferenciadas sobre a implementação do ensino de Ciências por investigação. Abd-el-khalick et al (2004) discutem que o termo investigação como prática de ensino de Ciências assume diferentes significados em diferentes países. Esses significados vão de concepções apropriadas nas reformas curriculares da década de 1950 e 1960 de promover o método científico na sala de aula às concepções que buscam superar essa visão, trazendo discussões sobre a natureza da Ciência e outras dimensões que constituem as condições de produção da Ciência.

Abd-el-khalick et al (2004) apontam 7 aspectos dicotômicos que consideram necessários discutir para conceber a investigação no ensino de Ciências. São eles:

(a) aprender ciência versus aprender sobre ciência; (b) ciência como busca da verdade versus ciência como atividade de resolução de problemas; (c) levantar e responder questões versus propor e revisar explicações e modelos; (d) ciência como atividade cognitiva versus ciência como atividade social; (e) demonstração de conceitos versus investigação de como sabemos e por que acreditamos nisso; (f) ciência hipotético-dedutiva versus modelo baseado em ciência; ( $\mathbf{g}$ ) ciência como processo de justificar e testar conhecimentos versus ciência como processo de descoberta e generalização de conhecimentos. (ABD-EL-KHALICK et al, 2004, p. 412, tradução nossa)

Todos esses aspectos fazem reflexão sobre a natureza da Ciência dentro do ensino de Ciências. Segundo Rudolph (2005) não é surpreendente que as 
recentes reformas curriculares no ensino de Ciências nos EUA dão ênfase paralelamente ao ensino por investigação e à natureza da Ciência ${ }^{13}$. Assim, as concepções atuais de ensinar Ciências por investigação buscam compreender a natureza da investigação científica dentro de outros contextos que eram silenciados na concepção de Ciência neutra a partir da aplicação do método científico nas propostas curriculares das décadas de 1950 e 1960.

Sandoval (2005) lista duas razões para que reflexões sobre a natureza da Ciência sejam incorporadas à prática do ensino de Ciências por atividades investigativas. A primeira é levar os alunos a compreenderem a natureza da investigação científica, contribuindo para a realização das atividades de investigação em sala de aula. A segunda refere-se ao desenvolvimento da concepção da atividade científica que os alunos possuem. Para o pesquisador, essa segunda razão é mais importante porque

(...) em sociedades democráticas contemporâneas, os cidadãos necessitam compreender a natureza do conhecimento e da prática científica a fim de participar eficazmente em decisões políticas e interpretar o significado das novas implicações científicas em suas vidas. (...) os cidadãos precisam entender o poder que a ciência, potencialmente, pode trazer para a tomada de decisões, bem como os limites da ciência. É preciso que os cidadãos compreendam a ciência, seus poderes e limites, não porque isso é bom para a ciência, mas porque isso é crucial para a democracia. (SANDOVAL, 2005, p. 637-638, tradução nossa)

Portanto, as novas perspectivas de ensinar Ciências por atividades investigativas assumem uma crítica a atividades de investigação com perspectivas simplistas e pouco reflexivas da Ciência ${ }^{14}$. E também que a investigação deve ir além das atividades técnicas instrumentalistas, como coleta e análise de dados, discutindo as relações e implicações sociais e políticas da investigação científica na sociedade, incluindo as controvérsias e limites da Ciência durante a realização das atividades.

Duschl (2005) aponta que a apropriação de atividades no ensino de Ciências por atividades investigativas deve estar em torno de três objetivos integrados: (a) as estruturas conceituais e cognitivas para compreensão do conhecimento científico; (b) as estruturas epistêmicas que contribuem no desenvolvimento das atividades investigativas nas aulas de Ciências e também avalia criticamente o processo realizado e (c) os processos sociais que remetem às condições de produção dos conhecimentos científicos. As estruturas sociais buscam compreender como o conhecimento é comunicado, discutido, levando em consideração o contexto social, político e econômico em que é produzido.

No contexto de trabalhos sobre ensino de Ciências por investigação no Brasil, a influência das discussões sobre natureza da Ciência e relações CTS no ensino de Ciências também se fazem presentes. Castro et al (2007) discutem sobre a proposta de um curso de formação de professores com a perspectiva investigava no qual discutem a necessidade em ir além do foco nos conhecimen- 
tos científicos com finalidade em si mesmos. Os pesquisadores discutem que a formação de professores nessa perspectiva de ensino deve enfocar

\begin{abstract}
(...) questões amplas e complexas do mundo contemporâneo, para que consigam desenvolver em (e com) seus alunos competências que os habilitem a fazer escolhas conscientes, que considerem os anseios coletivos, que ultrapassem os interesses privados e que sejam comprometidas com a segurança pessoal, coletiva e com a preservação do ambiente e do mundo. (CASTRO et al, 2007, p. 8)
\end{abstract}

Esse trabalho se apropria da abordagem CTSA (Ciência, Tecnologia, Sociedade e Ambiente) para discutir a formação de professores de Ciências na perspectiva investigativa. Outro trabalho dentro dessa discussão é o de Penha \& Vianna (2007) que também associa o enfoque CTS (Ciência, Tecnologia e Sociedade) com o ensino de Química por atividades investigativas. Esse trabalho, dentro do contexto educativo investigativo proposto, apresenta "um modo alternativo de estruturação de novos conceitos que estão relacionados com as evoluções tecnológicas que transformam nossa sociedade e com a instrumentalização dos estudantes para sua inserção social e no mundo do trabalho" (PENHA \& VIANNA, 2007, p. 2). Já Grynszpan et al (2007) não assume explicitamente a abordagem CTS no ensino de Ciências por atividades de investigação científica, mas se apropriam de uma discussão política importante das relações entre os conhecimentos científicos e a tomada de decisões para uma sociedade democrática. Os pesquisadores apontam que, durante o desenvolvimento de projetos de investigação em uma escola, houve discussões sobre as relações dos conhecimentos científicos com impactos ambientais locais. Essas discussões culminaram com a mobilização da comunidade escolar em manifestações sociais contra um acidente ecológico ocorrido no rio que passa na cidade onde o colégio se localiza. Esse trabalho remete ao que Sandoval (2005) discute sobre a importância de trabalhar perspectivas críticas no ensino de Ciências por atividades de investigação científica, a fim de formar cidadãos ativos na construção de uma sociedade mais democrática. Assim, os trabalhos de Castro et al (2007), Penha \& Vianna (2007) e Grynszpan et al (2007) buscam superar a visão da investigação científica neutra no ensino de Ciências, assumindo uma perspectiva da atividade científica com algo dinâmico dentro de contexto social, ético, político, contrapondo a visão de que a Ciência está separada da sociedade.

No contexto atual da pesquisa em Educação em Ciências no Brasil, de acordo com o levantamento realizado por Trópia (2009) de artigos apresentados na $1^{\mathrm{a}}$ a $6^{\mathrm{a}}$ edição do ENPEC (Encontro Nacional de Pesquisa em Educação em Ciências) e de revistas nacionais especializadas na área, há um aumento considerável ao longo dos anos (1997-2007) de pesquisas sobre o ensino de Ciências por atividades investigativas. No entanto, apenas algumas dessas pesquisas discutem sobre os princípios teóricos que fundamentam a prática de ensino de Ciências por investigação. Dessas, destaco as pesquisas de Nascimento \& Carvalho (2001, 2007), Munford \& Lima (2007), Praia, Gil-Pérez \& Vilches (2007), Sá et al (2007). 
Nascimento \& Carvalho (2001, 2007) discutem que a apropriação da prática científica no ensino de Ciências tem como fundamento possibilitar aos alunos uma concepção de Ciência histórica e humana. Praia, Gil-Pérez \& Vilches (2007) explicitam que planejar o ensino de Ciências como uma atividade próxima à investigação científica remete ao papel de discutir a natureza da Ciência na Educação e também as implicações tecnocientíficas na sociedade. Esses fundamentos estão de acordo com as mais recentes perspectivas do ensino de Ciências por investigação.

Sá et al (2007) apontam uma questão fundamental que é a distinção das características do ensino investigativo com às características da investigação científica.

Entendemos que essa distinção entre as práticas sociais e culturais dos estudantes em ambientes escolares e as práticas sociais dos cientistas seja uma condição para que possamos avançar no entendimento do que significa um 'ensino investigativo' (Sá et al, 2007, p. 5).

Geralmente os conhecimentos escolares são apresentados de forma descontextualizada de sua origem, negligenciando o processo de sua geração, o que produz interpretações do conhecimento como estático, imutável. No entanto, a forma como os conhecimentos científicos são produzidos em instituições de pesquisa se mostra diferente: os conhecimentos estão associados ao contexto social em que estão inseridos e sofrem frequentemente um processo de renovação e reformulação. Uma das possibilidades de entender essas diferenças entre o conhecimento que é produzido nas instituições de pesquisa e o que é apresentado na escola é compreender que, nesses diferentes contextos, os conhecimentos científicos assumem papéis diferenciados. No entanto, apesar desses distintos papéis, o que a abordagem do ensino de Ciências por investigação levanta é que é necessário associar na escola os conhecimentos escolares com as condições de produção dos conhecimentos científicos. Esse ponto é levantado a fim de ir contra uma visão equivocada da Ciência em que os conhecimentos científicos são apresentados sem história, contexto social, como imutáveis e fundamentados em verdades absolutas.

Entendo que os conhecimentos escolares se referem aos conhecimentos científicos, porém as condições de produção dos discursos são diferenciadas. O conhecimento escolar passa por um processo de mediação didática, sendo constituído por discursos diferentes do científico, como o pedagógico. No entanto, Almeida (2004) enfatiza que apesar de sofrer essa mediação didática, o conhecimento escolar não deve "descaracterizar o que é aparentemente básico na construção da Ciência” (ALMEIDA, 2004, p. 64). Isso se remete às práticas educativas em Ciências (conhecimento escolar) que devem discutir sobre os modos e condições de produção dos conhecimentos científicos, sobre a leitura do mundo que esses conhecimentos possibilitam fazer e também as que não 
possibilitam, ou seja, seus limites, suas possibilidades e suas implicações na sociedade. Enfim, que os conhecimentos escolares se refiram aos conhecimentos científicos, mas também sobre os conhecimentos científicos.

Dentro dessa perspectiva, Munford \& Lima (2007) se apropriam do trabalho de Paula (2004) para discutir sobre o ensino de Ciências por investigação. Paula (2004) discute como a Ciência escolar pode contribuir como instrumento para a compreensão da atividade científica e aponta três dimensões que o ensino de Ciências deve promover: (a) aprender Ciências, (b) aprender a fazer Ciências e (c) aprender sobre Ciências. Aprender Ciências remete ao processo em que o estudante tem a possibilidade de acesso aos conhecimentos científicos já consolidados. Aprender a fazer Ciências implica em "desenvolver habilidades associadas à produção de conhecimento confiável ou avaliação de proposições e 'fatos' atribuídos às Ciências" (PAULA, 2004, p. 300). Aprender sobre Ciências compreende levar o aluno a estabelecer relações tanto com os métodos de investigação quanto com as dinâmicas sociais que caracterizam as Ciências como um empreendimento cultural e social. De acordo com Paula (2004), as três dimensões são intrinsecamente ligadas, enfatizando que geralmente o ensino de Ciências prioriza os produtos do conhecimento científico, o aprender Ciências. Essa perspectiva produz uma visão equivocada e desarticulada da Ciência, inibindo "diversas contribuições potenciais da Educação escolar para a formação de sujeitos críticos e capazes de exercer alguma autonomia intelectual" (PAULA, 2004, p. 23).

Assim, dois pontos parecem ser consenso como pressupostos teóricos entre os pesquisadores: primeiro, há uma distinção entre os conhecimentos escolares e os conhecimentos científicos; segundo, aprender sobre Ciências aspectos epistêmicos e sociais - é tão importante quanto aprender Ciências. Nessa perspectiva de ensino, o aprender sobre Ciências ocupa uma posição de objeto pedagógico nas aulas de Ciências, a fim de aprimorar a compreensão dos alunos sobre Ciências e sobre o mundo em que vivem. A compreensão do que seja aprender sobre Ciências ou até que ponto há limites e possibilidades de articular os conhecimentos escolares com os conhecimentos científicos é que fundamentará o ensino de Ciências por investigação ${ }^{15}$.

\section{CONSIDERAÇÕES FINAIS}

O ensino de Ciências por investigação vem se difundindo no contexto educacional brasileiro. No entanto, as perspectivas mais recentes dessa prática de ensino se estabeleceram a partir de novas leituras da concepção do que é ensinar por investigação concebida em momentos históricos diferenciados. Essas novas leituras são estabelecidas, dentre outros aspectos, pela concepção do que é a atividade científica. Assim, este trabalho propôs apresentar perspectivas diferenciadas de ensinar Ciências por atividades investigativas em diferentes períodos históricos. 
Apesar de não referir especificamente sobre o ensino de Ciências, Dewey propõe a perspectiva investigativa no contexto escolar no início do século XX. A investigação para Dewey se constituía na execução do método científico em busca de uma sociedade mais democrática e do desenvolvimento social. As ideias de Dewey se constituem em um modelo de desenvolvimento muito comum no século XX em que os conhecimentos científicos proporcionariam o progresso, o desenvolvimento social, por isso ele propõe que a atividade científica fosse trabalhada na Educação Básica. Essa proposta se constituía na realização das etapas do método científico: definição do problema, elaboração de hipóteses, sugestão de verificação da hipótese, desenvolvimento e aplicação de testes experimentais e obtenção de resultados e conclusão.

O segundo período histórico evidenciado no trabalho foi entre 1950 e 1960 em que tanto no Brasil quanto no exterior foram elaboradas reformas curriculares para o ensino de Ciências. Os materiais didáticos produzidos nessa época tinham ênfase na execução de atividades de investigação científica a partir do planejamento e execução de experimentos, proporcionando aos alunos realizarem o método científico. A investigação científica era concebida como uma atividade neutra, ou seja, as condições de produção, bem como as implicações da produção científica para a sociedade eram silenciadas nesse período. O modelo de desenvolvimento em que mais Ciência e mais Tecnologia geraria mais riqueza e bem-estar social para os países era um dos pressupostos que impulsionava os investimentos no ensino de Ciências. Assim, desenvolver nas crianças o interesse pela Ciência pela execução do método científico levaria a uma nova geração de cientistas que impulsionariam o desenvolvimento científico, econômico e social.

As perspectivas mais recentes do ensino de Ciências por investigação têm início com a retomada dessa prática de ensino no final da década de 1980. Essas novas leituras trazem questões importantes para discussão no ensino de Ciências: a natureza da Ciência e as relações e implicações entre a Ciência e a Sociedade. Nesse contexto não há ênfase apenas na execução de atividades empírico-experimentais pouco reflexivas, mas na discussão da importância da atividade científica no mundo contemporâneo, bem como seus limites e controvérsias. Nessa nova leitura do ensino de Ciências por investigação o modelo que mais Ciência levaria necessariamente ao desenvolvimento da sociedade começa a ser questionado. As discussões sobre a natureza da Ciência contemplam a atividade científica como uma atividade humana, histórica e social, vinculada a interesses políticos e econômicos. Deste modo, a prática de ensinar Ciências por investigação passa a contemplar com os alunos: uma visão crítica da Ciência, as condições de produção e as implicações sociais da atividade científica, a fim de formar cidadãos que não assumam uma postura passiva frente às implicações científicas em suas vidas, mas que utilizem essas discussões para a tomada de decisões e para a construção de uma sociedade democrática.

Assim, assinalo que a idéia de aproximar a prática dos cientistas ao contexto da Educação Básica e especificamente ao ensino de Ciências assumiu 
diferentes posições em diferentes momentos históricos no Brasil e no exterior. Tendo em vista as condições de produção das práticas e dos discursos do ensino de Ciências por atividades investigativas em cada período histórico no Brasil, como o contexto social, político e econômico, diferentes sentidos da atividade científica foram propostos na pesquisa em Educação em Ciências e para a Educação Básica.

Dentro da reflexão de como os discursos e as práticas sobre o ensino de Ciências foram se constituindo no Brasil, ressalto como proposta para discussões futuras o movimento político na apropriação de propostas estrangeiras para o ensino de Ciências no Brasil a partir da segunda metade do século XX. Uma reflexão sobre as intencionalidades da Fundação Ford e de outras instituições estrangeiras de fomento que viabilizaram reformas curriculares das décadas de 1950 e 1960, instituindo a prática de investigação no ensino de Ciências, possivelmente contribuiria para entender os discursos do ensino de Ciências por atividades investigativas e da Ciência na Educação Básica naquele momento histórico no Brasil. O modelo de Ciência ou de ensino de Ciências, que se construía no país a partir da tradução dos materiais didáticos estrangeiros vindos de países dos quais que o Brasil é, historicamente, dependente econômico, provavelmente possui relações políticas e econômicas que não são contempladas nas pesquisas em Educação em Ciências.

As propostas mais recentes do ensino de Ciências por atividades investigativas no Brasil também possuem relações próximas com as reformas curriculares dos EUA e Inglaterra a partir da década de 1980. Os documentos oficiais dessas reformas nos EUA, como o AAAS (1990) e o NRC (1996), estão presentes como referência bibliográfica na grande maioria das pesquisas em ensino de Ciências por investigação no Brasil. Assim, analisar como os discursos oficiais estrangeiros sobre o ensino investigativo são apropriados e ressignificados para o contexto brasileiro atualmente possibilitaria uma maior compreensão dos sentidos e das concepções de Ciência veiculadas nas propostas de ensino de Ciências por atividades investigativas desenvolvidas no Brasil. 


\section{NOTAS}

1 Uma versão inicial deste trabalho foi apresentada no VII Encontro Nacional de Pesquisa em Educação em Ciências em Florianópolis (UFSC) em 2009.

2 O sistema de ensino obrigatório nos EUA tem duração de 13 anos englobando dois níveis de ensino: a elementary school, que corresponde ao Ensino Fundamental no Brasil, onde o aluno ingressa com cinco anos de idade (kindergarten) e permanece até a $8^{a}$ série, e a high school, que corresponde ao Ensino Médio, que engloba da $9^{\mathrm{a}}$ à $12^{\mathrm{a}}$ série.

3 Rodrigues \& Borges (2008) e Zompero \& Laburu (2010) apontam perspectivas de ensinar Ciências por investigação no século XIX nos EUA e Europa.

4 De acordo com Cunha (2001), o New Deal consistiu em um amplo arranjo de medidas governamentais para apoiar organizações financeiras, comerciais e industriais em dificuldades, aliado a um conjunto de iniciativas visando fomentar empregos e, consequentemente, melhorias na vida dos trabalhadores do campo e da cidade.

5 Cunha (2001) resgata o contexto políticossocial vigente na época em que Dewey produz sua obra.

6 De acordo com Marandino et al (2009), o apoio de capital estrangeiro para as atividades do IBECC vieram pelas Fundações Ford e Rockefeller, pela União Pan-Americana e pela Agência Norte-Americana para o Desenvolvimento Internacional (USAID). Barra e Lorenz (1986) apontam também a Fundação Nuffield da Inglaterra como subsidiária de capital para o IBECC.

${ }^{7}$ Marandino et al (2009, p. 57) listam os projetos curriculares desenvolvidos pelos programas norteamericanos.

8 A versão verde do BSCS foi traduzida e adaptada entre 1961-64 e a versão azul em 1967 (BARRA \& LORENZ, 1986). Não há referências de tradução da versão amarela do BSCS. Ferreira \& Selles (2005) apresentam algumas informações sobre o processo de tradução da versão azul do BSCS.

9 Esses cursos eram treinamentos para os professores aplicarem os materiais traduzidos pelo IBECC em sala de aula, como, por exemplo, o PSSC e BSCS.

10 Essa perspectiva distorcida da Ciência também se apresenta em algumas práticas de ensinar Ciências por atividades investigativas no início do século XXI (TRÓPIA, 2009).

11 Acrescento que o contexto histórico e político também influenciarão no que é ou o que pode ser observado em uma investigação científica.

12 Líbano, EUA, Israel, Venezuela, Austrália e China.

13 Ver: American Association for the Advancement of Science (AAAS, 1990) e National Research Council (NRC, 1996)

14 Chinn \& Malhotra (2002), Anderson (2002) e Newman et al (2004) mostram concepções simplistas e superficiais sobre a investigação científica, evidenciando os dilemas vivenciados nas práticas de ensino de Ciências por investigação.

15 Além dos argumentos apresentados da relação entre os conhecimentos escolares e os conhecimentos científicos de referência para fundamentar as perspectivas mais recentes do ensino de Ciências por atividades investigativas, outras questões são importantes para a constituição dessa prática de ensino. Estudos apontam que o movimento de apropriação dos conhecimentos científicos que ocorre nas instituições escolares não possui as Ciências de referência como único aporte para a constituição dos currículos e das práticas escolares (FERREIRA \& SELLES, 2005; MARANDINO et al, 2009). Elementos da cultura escolar nas quais as práticas educativas estão inseridas a partir de finalidades históricas e sociais específicas da escolarização também constituem as práticas de ensinar Ciências através de atividades investigativas. Poucos trabalhos priorizam a discussão da cultura escolar na constituição do ensino de Ciências por atividades investigativas. Aponto o trabalho de Julio \& Vaz (2007) que investiga atividades de investigação escolar em Física a partir de "Grupos de Trabalho", problematizando elementos da cultura escolar na prática de ensino proposta. 


\section{REFERÊNCIAS BIBLIOGRÁFICAS}

ABD-EL-KHALICK, F, et al. Inquiry in Science Education: International Perspectives. Science Education, v. 88, n. 3, p. 397-419, 2004.

ALMEIDA, M. J. P. M. Discursos da Ciência e da Escola: ideologia e leituras possíveis. Campinas: Mercado das Letras, 2004.

AMERICAN ASSOCIATION FOR THE ADVANCEMENT OF SCIENCE (AAAS). Benchmarks for Science literacy: project 2061. New York: Oxford University Press, 1993.

ANDERSON, R. D. Reforming Science Teaching: What Research says about Inquiry. Journal of Science Teacher Education, v. 13, n. 1, p. 1-12, 2002.

BARRA, V. \& LORENZ, K. M. Produção de materiais didáticos de Ciências no Brasil, período: 1950 a 1980. Ciência e Cultura, v. 38, n. 3, p. 1970-1983, 1986.

BARROW, L. H. A Brief History of Inquiry: From Dewey to Standards. Journal of Science Teacher Education, v. 17, n. 3, p. 265-278, 2006.

CASTRO, R. S, et al. CTSA: uma abordagem para enfrentar a complexidade do mundo contemporâneo. In: VI Encontro Nacional de Pesquisa em Educação em Ciências, Florianópolis, 2007. Anais do VI ENPEC, Belo Horizonte: ABRAPEC, 2007.

CHINN, C. A.; MALHOTRA, B. A. Epistemologically authentic inquiry schools: a theorical framework for evaluating inquiry tasks. Science Education, v. 86, n. 2, p. 175-218, 2002.

CUNHA, M. V. John Dewey: Filosofia, Política e Educação. Perspectiva, v. 19, n. 2, p. 371-388, 2001. DEWEY, J. Democracia e educação: introdução à Filosofia da Educação. 3 ed. São Paulo: Companhia Editora Nacional, 1959.

Experiência e Educaşão. São Paulo: Companhia Editora Nacional, 1971.

DUSCHL, R. The high school laboratory experience: reconsidering the role of evidence, explanation and language of Science. Paper commissioned by the National Research Council on the Role of the Laboratory in High School Science, 2005. Acesso em 10/11/2008 http://www7.nationalacademies.org/bose/RDuschl_comissioned_paper_71204_HSLabs_Mtg.pdf

Science Education in Three-Part Harmony: Balancing Conceptual, Epistemic, and Social Learning Goals. Review of Research in Education, v. 32, n. 1, p. 268-291, 2008.

FERREIRA, M. S.; SELLES, S. E. Entrelaçamentos históricos das Ciências Biológicas com a disciplina escolar Biologia: investigando a versão azul do BSCS. In: V Encontro Nacional de Pesquisa em Educação em Ciências, 2005, Bauru, SP. Atas do V ENPEC, Bauru, SP: ABRAPEC, 2005.

GRYNSZPAN, D. \& AZEVEDO, S. M. G. O "ABC na Educação Científica - Mãonamassa": construindo uma proposta de avaliação educacional com base em pesquisa sobre a implementação do projeto. In: VI Encontro Nacional de Pesquisa em Educação em Ciências, Florianópolis, 2007. Anais do VI ENPEC, Belo Horizonte: ABRAPEC, 2007.

JULIO, J; VAZ, A. Grupos de alunos como grupos de trabalho: um estudo sobre atividades de investigação. Revista Brasileira de Pesquisa em Educação em Ciências, v. 7, n. 2, 2007.

KRASILCHIK, M. Reformas e Realidade: o caso do ensino de Ciências. São Paulo em Perspectiva, v. 14, n. 1, p. 85-93, 2000.

MARANDINO, M; SELLES, S. E; FERREIRA, M. S. Ensino de Biologia: histórias e práticas em diferentes espaços educativos. São Paulo: Cortez, 2009.

MOREIRA, M. A; OSTERMANN, F. Sobre o ensino do Método Científico. Caderno Catarinense de Ensino de Física, v. 10, n. 2, p. 108-117, 1993.

MUNFORD, D; LIMA, M. E. C. C. Ensinar Ciências por investigação: em quê estamos de acordo? Ensaio - Pesquisa em Educação em Ciências, v. 9, n. 1, 2007.

NASCIMENTO, V. B; CARVALHO, A. M. P. Visão de Ciência de estudantes do Ensino Médio e Ensino por Investigação. In: ENCONTRO NACIONAL DE PESQUISA EM EDUCAÇÃO EM CIÊNCIAS, 3, Atibaia, SP, 2001. Atas do III ENPEC, Porto Alegre: ABRAPEC, 2001.

A natureza do conhecimento científico e o Ensino de Ciências. In: ENCONTRO

NACIONAL DE PESQUISA EM EDUCAÇÃO EM CIÊNCIAS, 6, Florianópolis, 2007. Anais do VI ENPEC, Belo Horizonte: ABRAPEC, 2007.

NATIONAL RESEARCH COUNCIL (NRC). National Science Education Standards. 
Washington, DC: National Academy Press, 1996.

NEWMAN, W. J. et al. Dilemmas of Teaching Inquiry in Elementary Science Methods. Journal of Science Teacher Education, v. 15, n. 4, p. 257-279, 2004.

PAULA, H. F. A ciência escolar como instrumento para a compreensão da atividade científica. 2004. Tese (Doutorado em Educação) - Faculdade de Educação, Universidade Federal de Minas Gerais, Belo Horizonte, 2004.

PENHA, S. P; VIANNA, D. M. A Física e a sociedade na TV. In: ENCONTRO NACIONAL DE PESQUISA EM EDUCAÇÃO EM CIÊNCIAS, 6, Florianópolis, 2007. Anais do VI ENPEC, Belo Horizonte: ABRAPEC, 2007.

PESSOA-PINTO, H. P. Crítica ao pragmatismo a partir de uma reflexão sobre o papel da ciência no projeto filosófico de John Dewey. 2004. Dissertação (Mestrado em Filosofia) - Universidade Federal de Santa Catarina. Florianópolis, 2004.

POSNER, G. J, et al. Accommodation of a Scientific Conception: Toward a Theory of Conceptual Change. Science Education, v. 66, n. 2, p. 211-227, 1982.

PRAIA, J; GIL-PÉREZ, D; VILCHES, A. O papel da natureza da Ciência na Educação para cidadania. Ciência \& Educação, v. 13, n. 2, p. 141-156, 2007.

RODRIGUES, B. A; BORGES, A. T. O ensino de Ciências por investigação: reconstrução histórica. In: ENCONTRO DE PESQUISA EM ENSINO DE FÍSICA, 9 2008, Curitiba, PR. Anais do XI Encontro de Pesquisa em Ensino de Física, São Paulo: Sociedade Brasileira de Física, 2008.

RUDOLPH, J. L. Inquiry, Instrumentalism and the Public Understanding of Science. Science Education, v. 89, n. 5, p. 803-821, 2005.

SÁ, E. F, et al. As características das atividades investigativas segundo tutores e coordenadores de um curso de especialização em Ensino de Ciências. In: ENCONTRO NACIONAL DE PESQUISA EM EDUCAÇÃO EM CIÊNCIAS, 6,Florianópolis, 2007. MORTIMER, E. F. (org.). Anais do VI ENPEC, Belo Horizonte: ABRAPEC, 2007.

SANDOVAL, W. A. Understanding students' practical epistemologies and their influence on learning through inquiry. Science Education, v. 89, n. 4, p. 634-656, 2005.

TEITELBAUM, K; APPLE, M. John Dewey. Currículo sem Fronteiras, v. 1, n. 2, p. 194-201, 2001

TRÓPIA, G. Relações dos alunos com o aprender no Ensino de Biologia por atividades investigativas. Dissertação (Mestrado em Educação Científica e Tecnológica) - Universidade Federal de Santa Catarina, Florianópolis: UFSC, 2009.

ZOMPERO, A. F. \& LABURÚ, C. E. O ensino por inquiry: aspectos históricos e as diferentes concepções desta perspectiva de ensino. In: CONGRESSO INTERNACIONAL CONFERENCE PROBLEM-BASED LEARNING, 2010, São Paulo, SP. Atas do Congresso Internacional Problem-Based Learning. São Paulo: [s.l], 2010.

Data recebimento: $16 / 02 / 2010$

Data aprovação: $28 / 08 / 2010$

Data versão final: $15 / 10 / 2010$ 
